\title{
Aspectos nutricionais em doentes renais crônicos em tratamento conservador: uma revisão integrativa
}

\author{
Nutritional aspects in chronic kidney patients under conservative treatment: an integrative \\ review
}
Aspectos nutricionales en pacientes renales crónicos en tratamiento conservador: una revisión integradora

Gibran Said Barbosa Lima1*.

\section{RESUMO}

Objetivo: Descrever por meio de uma análise da literatura científica sobre os aspectos nutricionais do paciente renal crônico em tratamento conservador. Métodos: Estudo de Revisão Integrativa de natureza qualitativa com abordagem descritiva e exploratória. Os artigos foram buscados nas bases de dados Lilacs, Scielo, Acervo+ e PubMed, seguidos de pré-análise, exploração do material, tratamento dos dados, interpretação dos resultados e elaboração das categorias temáticas do estudo, dispostos em quadro sinóptico para a definição e composição das categorias analíticas que responderam à pergunta norteadora da pesquisa. Resultados: Foram incluídos nove estudos de acordo com os critérios estabelecidos. Pode-se observar que o tratamento conservador é um regime terapêutico que apresenta desafios ao paciente, pois não é fácil mudar os hábitos alimentares como deixar de comer proteínas, evitar o sódio e limitar-se no consumo de líquidos, exigindo a adesão tanto do paciente como de familiares para que não apareçam complicações mais graves. Considerações finais: As restrições nutricionais representam o maior desafio do tratamento conservador da Doença Renal Crônica (DRC), pois exige mudança dos hábitos não apenas do paciente, mas de todos os familiares. A dieta para indivíduos com DRC devem ser adequadas às necessidades individuais, prevenindo desnutrição e garantindo a adesão dos clientes.

Palavras-chave: Aspectos nutricionais, Tratamento conservador, Pacientes renais crônicos.

\begin{abstract}
Objective: To describe through an analysis of the scientific literature on the nutritional aspects of chronic renal patients undergoing conservative treatment. Methods: Qualitative Integrative Review study with a descriptive and exploratory approach. The articles were searched in the Lilacs, Scielo, Acervo+ and PubMed databases, followed by pre-analysis, material exploration, data treatment, interpretation of results and elaboration of the study's thematic categories, arranged in a synoptic table for the definition and composition of the analytical categories that answered the guiding question of the research. Results: Nine studies were included according to the established criteria. It can be observed that conservative treatment is a therapeutic regimen that presents challenges to the patient, as it is not easy to change eating habits such as stopping eating proteins, avoiding sodium and limiting the consumption of liquids, requiring both patient compliance family members so that more serious complications do not appear. Final considerations: Nutritional restrictions represent the biggest challenge for conservative treatment of Chronic Kidney Disease (CKD), as it requires changing habits not only of the patient, but of all family members. The diet for individuals with CKD should be tailored to individual needs, preventing malnutrition and ensuring client compliance.
\end{abstract}

Key words: Nutritional aspects, Conservative treatment, Chronic kidney patients.

1 Universidade Federal do Amazonas (UFAM), Manaus - AM. *E-mail: gibransaid@gmail.com 


\section{RESUMEN}

Objetivo: Describir, a través del análisis de la literatura científica, los aspectos nutricionales de los pacientes renales crónicos en tratamiento conservador. Métodos: Estudio de Revisión Cualitativa Integrativa con enfoque descriptivo y exploratorio. Los artículos fueron buscados en las bases de datos Lilacs, Scielo, Acervo+ y PubMed, seguido de preanálisis, exploración de materiales, procesamiento de datos, interpretación de resultados y elaboración de las categorías temáticas del estudio, ordenados en una tabla sinóptica para la definición y composición de las categorías analíticas que respondieron a la pregunta orientadora de la investigación. Resultados: Se incluyeron nueve estudios según los criterios establecidos. Se puede observar que el tratamiento conservador es un régimen terapéutico que presenta desafíos para el paciente, ya que no es fácil cambiar los hábitos alimentarios como dejar de ingerir proteínas, evitar el sodio y limitar el consumo de líquidos, requiriendo tanto el cumplimiento del paciente por los familiares para que no aparecen complicaciones más graves. Consideraciones finales: Las restricciones nutricionales representan el mayor desafío para el tratamiento conservador de la enfermedad renal crónica (ERC), ya que requiere un cambio de hábitos no solo del paciente, sino de todos los miembros de la familia. La dieta para las personas con ERC debe adaptarse a las necesidades individuales, previniendo la desnutrición y asegurando el cumplimiento del cliente.

Palabras clave: Aspectos mutricionales, Tratamiento conservador, Pacientes renales crónicos.

\section{INTRODUÇÃO}

Atualmente as doenças crônicas não transmissíveis (DCNT) são a maior causa de adoecimento e mortalidade no mundo (MARINHO ELS, et al., 2018). Entre essas destaca-se a Doença Renal Crônica (DRC) que é considerada uma doença progressiva e irreversível, apresentando anormalidades das funções endócrinas, tubular e glomerular dos rins, exibindo como característica principal a diminuição do filtrado glomerular (> $60 \mathrm{ml} / \mathrm{min} / 1,73 \mathrm{~m}^{2}$ ) durante um período de três meses ou mais, com ou sem lesão renal, com consequente desequilíbrio hidroeletrolítico e metabólico, conforme a diretriz pela Kidney Disease Outcome Quality Initiative (KDOQI) (K/DOQI, 2002; RIELLA MC, 2003).

Avalia-se o comprometimento e a diminuição das funções renais de acordo com os seguintes critérios: estágio zero, apresentando risco aumentado, com Taxa de Filtração Glomerular (TFG) maior ou igual a 90 $\mathrm{ml} / \mathrm{min} / 1,73 \mathrm{~m}^{2}$, com presença de condicionantes para a doença renal crônica; estágio um, apresentando lesão renal e TFG dentro dos parâmetros considerados normais ou já aumentada; estágio dois, apresentando lesão renal controlada e leve diminuição da TFG; estágio três, apresentando diminuição moderada da TFG; estágio quatro, apresentando redução grave da TFG; estágio cinco, apresentando a Doença Renal Crônica terminal (K/DOQI, 2002).

Essa doença tem se mostrado mundialmente como um problema de saúde pública, pois é muito mais frequente do que até então se considerava e sua evolução clínica está associada a taxas altas de morbimortalidade (COUSER WG, et al., 2011). No Brasil, os dados de incidência e prevalência de colapso de função renal são altos e o prognóstico ainda é desafiador, afinal os custos do tratamento da doença são elevadíssimos e consequentemente impeditivos. O Sistema Único de Saúde (SUS) teve 12,97\% das despesas no triênio 2013-2015 com despesas relacionadas ao tratamento e internação da DRC, doenças agregadas e exames para diagnóstico/tratamento. A DRC e as doenças associadas corresponderam a 1,82\% e 5,79\% das internações hospitalares por todas as causas no Brasil, e 2,87\% e 10,10\% de todas as despesas, respectivamente (ALCALDE PR e KIRSZTAJN GM, 2018).

A Sociedade Brasileira de Nefrologia no censo de 2017 mostrou que houve uma progressão da doença nos últimos anos, enquanto nos anos 2000 havia mais de 42 mil pacientes em diálise no país, em 2017 já passavam de 126 mil (SBN, 2017). Trata-se de uma doença com multiplicidade etiológica, sendo as principais etiologias as glomerulopatias primárias, doenças crônicas (Diabetes Mellitus e Hipertensão Arterial), doenças de cunho hereditário e congênitas (GRICIO TC, et al., 2009). 
Na maioria dos casos a DRC é assintomática, sendo sintomática quando a doença está em fase avançada (ROSO CC, et al., 2013), podendo apresentar cansaço, falta de concentração, confusão mental, cefaleia, diminuição do apetite, rotina de sono alterada, edemas de membros inferiores, pele ressecada e micção frequente à noite (RASCHE J e BOSCO SMD, 2015).

Com o agravamento da DRC o processo inflamatório pode levar à má interpretação dos parâmetros nutricionais, aumentando as medidas antropométricas e testes bioquímicos, como albumina sérica, hemoglobina, transferrina e ferritina (KALANTAR-ZADEH K, et al., 2004). Além disso, evidências clínicas mostram que mediadores inflamatórios também podem induzir anorexia, anemia, proteólise muscular, redução de síntese protéica com hipoalbuminemia (GABAY C e KUSHNER I, 1999).

Com o diagnóstico de DRC instituído, caberá ao médico discutir com o paciente e seus familiares a melhor alternativa terapêutica para retardar sua progressão, pois são vários os fatores que podem influenciar nessa escolha, por exemplo, as características clínicas individuais, a preferência do médico e paciente, bem como a localização geográfica e a condição econômica do paciente (SZUSTER DAC, et al., 2012). As alternativas terapêuticas são: diálise, transplante ou tratamento conservador sem suporte dialítico (CASTRO MCM, 2019).

O tratamento conservador consiste em controlar os fatores de risco para o avanço da doença, bem como para ocorrências cardiovasculares e possível óbito precoce, objetivando manter a taxa de filtração glomerular pelo maior tempo de progressão possível e melhorar as condições clínicas, psicológicas e sociais do paciente (UNA-SUS/UFMA, 2014). Este tratamento ocorre por meio de vários medicamentos, dietas muito restritas, restrição hídrica e frequente realização de exames de laboratório e de imagem. Ou seja, o objetivo final desse tratamento é manter o paciente em condição clínica estável e compatível com o estágio da sua doença renal, além, é claro, de emocionalmente estruturado (ROSO CC, et al., 2013).

De acordo com Perusso FKG, et al. (2019) a nutrição exerce um importante papel na avaliação e na terapêutica das doenças renais, incluindo também o aconselhamento dietético individualizado, visando o controle e a prevenção das complicações da DRC. Cabe aqui destacar a grande relevância no que diz respeito ao estado nutricional do paciente com DRC para o planejamento de intervenções efetivas às suas necessidades, pois é sabido que a obesidade é um fator causador da doença e suas diversas complicações. Por outro lado, a desnutrição é frequente e pode cooperar para o aumento da morbimortalidade (WING MR, et al., 2014).

Pereira RA, et al. (2020) referem que novas abordagens tem sido utilizadas para melhor nortear os pacientes com doença renal crônica no que diz respeito a terapia nutricional, considerando desde os principais nutrientes (proteínas, fósforo, potássio e sódio) que precisam ser ajustados devido às alterações nas funções renais, como ainda a adoção de padrões alimentares agregados tanto a prevenção quanto a terapêutica da DRC, ou seja, ressaltam a reflexão sobre o processo de ressignificação do conceito de dieta saudável para que seja possível a sua promoção diante do ser biopsicossocial.

Diante do exposto, o presente estudo tem como objetivo descrever os aspectos nutricionais do paciente renal crônico em tratamento conservador.

\section{MÉTODOS}

O presente trabalho é um estudo de revisão bibliográfica do tipo revisão integrativa da literatura sobre os aspectos nutricionais do paciente renal crônico em tratamento conservador, a qual faz análise de estudos relevantes, sintetiza o conhecimento produzido e leva ao incremento de conclusões gerais a respeito da temática.

É um método de pesquisa que contempla as seguintes etapas: seleção das hipóteses ou da questão da pesquisa; critérios para a seleção da amostra; busca na literatura, avaliação dos dados; análise dos dados; e apresentação dos resultados.

A pesquisa foi orientada a partir da seguinte questão: Quais os aspectos nutricionais do paciente renal crônico em tratamento conservador descritos na literatura científica? 
As buscas das publicações ocorreram no período de setembro a dezembro de 2020, na plataforma Biblioteca Virtual de Saúde (BVS), onde foram realizadas as pesquisas nas bases de dados: Literatura LatinoAmericana e do Caribe em Ciências da Saúde (LILACS), Scientific Electronic Library Online (SCIELO), ACERVO+ e PUBMED, por meio de termos cadastrados no site dos Descritores em Ciências da Saúde (DeCS): "Aspectos Nutricionais", "Tratamento Conservador", "Pacientes Renais Crônicos", sendo realizado cruzamento dos termos mediante o uso do operador booleano "AND".

Foram aplicados os seguintes critérios de inclusão foram: artigos disponíveis em meio eletrônico, texto completo abordando o tema, inseridos nas bases de dados nacionais e internacionais, nos idiomas inglês, português e espanhol e terem sido publicados no período de 2010 a 2020. E como critérios de exclusão foram: reflexões, resumos de anais, revisões bibliográficas, artigos que não estejam na íntegra, outros idiomas, livros, documentos repetidos em base de dados, fora do período de interesse, estudos duplicados e que não atendessem a temática proposta, conforme Figura 1 a seguir.

Figura 1- Fluxograma da seleção dos estudos para esta revisão.

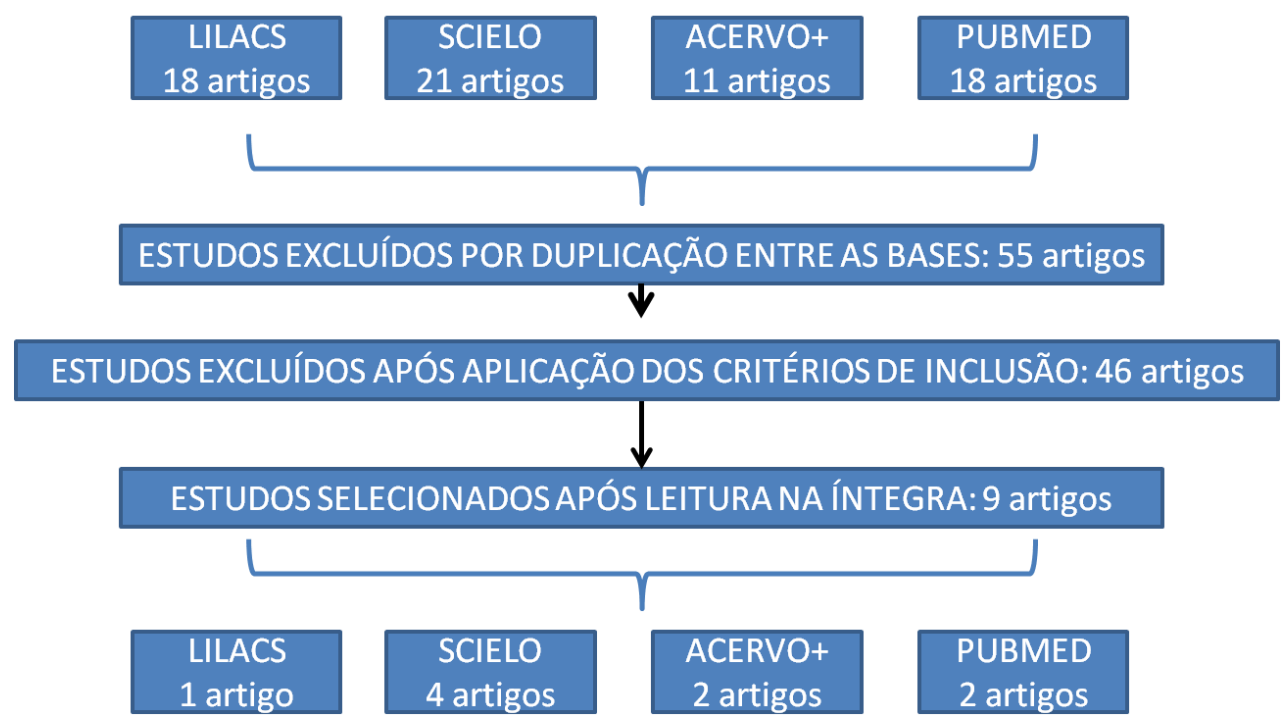

Fonte: Lima GSB, 2021.

A análise dos dados deu-se a partir da proposta de Minayo MCS (2012) para estudos qualitativos, incluindo: pré-análise, exploração do material e tratamento dos dados, interpretação dos resultados e elaboração das categorias temáticas do estudo.

Após a seleção e análise crítica, os estudos foram dispostos em quadro sinóptico contendo título, autor, ano de publicação, base de dados, delineamento e principais resultados para a definição e composição das categorias analíticas que responderam à pergunta norteadora da pesquisa.

\section{RESULTADOS}

No primeiro momento da pesquisa, com os descritores específicos resultou em 68 artigos que após filtragem totalizou em 13 artigos, que ao serem identificados como adequados ao propósito deste trabalho foram arquivados para posterior leitura e análise crítica.

Deu-se neste momento prosseguimento a leitura das publicações selecionadas. Passou-se a buscar acesso aos resumos de todos os exemplares, sendo cuidadosamente revisado em leituras disciplinares, avaliando os conteúdos pertinentes à temática. Após a análise criteriosa das publicações mais relevantes, definiu-se a amostra final em nove artigos que atenderam aos critérios de seleção. A seguir o Quadro 1 apresenta os autores, ano de publicação do periódico e os principais achados. 
Quadro 1- Apresentação da síntese dos estudos selecionados para esta revisão.

\begin{tabular}{|c|c|c|c|}
\hline $\mathbf{N}$ & Autores (Ano) & Base Científica & Principais achados \\
\hline 1 & MANSUR HN, et al. (2012) & SCIELO & $\begin{array}{l}\text { Estudo quantitativo. A fragilidade foi caracterizada em } 36 \% \text { dos pacientes em TC, } \\
37,8 \% \text { em } \mathrm{HD} \text { e } 47,8 \% \text { em DP. Foi diagnosticada em } 36,8 \% \text { dos pacientes com idade } \\
\text { entre } 20 \text { e } 40 \text { anos e } 40,3 \% \text { daqueles entre } 41 \text { e } 60 \text { anos. A fragilidade associou-se } \\
\text { significativamente ao uso de vitamina } D(r=0.16 ; p=0.03) \text {, hemoglobina }(r=-0.14 \text {; } \\
p=-0.02) \text { e paratormônio intacto ( } r=0.16 ; p=0.03) \text {. A fragilidade é frequente entre } \\
\text { os pacientes com DRC em tratamento conservador e dialítico, mesmo naqueles não } \\
\text { idosos. Nos pacientes estudados, o fenótipo de fragilidade se associou com o não } \\
\text { uso de vitamina } D \text {, menores níveis séricos de hemoglobina e níveis mais elevados de } \\
\text { paratormônio. }\end{array}$ \\
\hline 2 & CASTRO MCM (2019) & ACERVO+ & $\begin{array}{l}\text { Estudo qualitativo. Independentemente da crença de que a restrição proteica retarda } \\
\text { a progressão da DRC, é importante adequar a dieta ao estágio da doença renal, pois } \\
\text { é uma poderosa ferramenta no controle dos sintomas da DRC. A excessiva ingestão } \\
\text { de proteínas, particularmente de origem animal, sobrecarrega o trabalho renal e } \\
\text { acelera a progressão da doença. Além da restrição proteica, na maioria das vezes } \\
\text { pode ser necessária a restrição de sal, para o controle da hipertensão arterial e do } \\
\text { edema, e a moderação no uso de determinadas frutas, legumes e verduras, para } \\
\text { controle do potássio sérico. }\end{array}$ \\
\hline 3 & THEES TYP, et al. (2018) & PUBMED & $\begin{array}{l}\text { Estudo quantitativo. A amostra foi composta por } 188 \text { indivíduos, } 59 \% \text { do sexo } \\
\text { masculino, com idade média de } 69,64 \pm 9,46 \text { anos, } 62,2 \% \text { não concluiu o ensino } \\
\text { fundamental e a renda per capita mediana foi inferior a um salário mínimo. A maioria } \\
\text { encontrava-se no estágio } 3 B(35,1 \%) \text { ou } 4 \text { da doença }(34 \%) \text {. Ambos os sexos } \\
\text { apresentaram altas prevalências de excesso de peso }(81,2 \% \text { dos adultos e } 56,1 \% \\
\text { dos idosos) e perímetro da cintura elevado }(80,9 \%) \text {. Sobre os exames bioquímicos, } \\
\text { verificou-se hipercolesterolemia em } 33 \% \text {, HDL baixo em } 39,7 \% \text { e glicemia de jejum } \\
\text { elevada nos diabéticos ( } 135,06 \pm 53,67 \mathrm{mg} / \mathrm{dll}) \text {. Os minerais foram adequados para a } \\
\text { maioria dos pacientes. Apenas idade, potássio e fósforo séricos foram diferentes entre } \\
\text { os estágios da DRC e a taxa de filtração glomerular apresentou correlação com idade, } \\
\text { IMC, potássio e fósforo. A avaliação do estado nutricional e dos exames bioquímicos } \\
\text { são fundamentais uma vez que possuem importante impacto no prognóstico e } \\
\text { qualidade de vida desses pacientes. }\end{array}$ \\
\hline
\end{tabular}




\begin{tabular}{|c|c|c|c|}
\hline $\mathbf{N}$ & Autores (Ano) & Base Científica & Principais achados \\
\hline 4 & CANHESTRO MR, et al. (2010) & SCIELO & $\begin{array}{l}\text { Estudo quantitativo. Os dados relativos à avaliação do conhecimento sobre as } \\
\text { características dos medicamentos e da dieta indicados no tratamento conservador. } \\
\text { Praticamente a totalidade dos informantes sabia que o uso dos medicamentos é parte } \\
\text { fundamental do tratamento. Na população estudada, } 73,3 \% \text { e } 56,0 \% \text { dos pacientes } \\
\text { tinham prescrição do bicarbonato de sódio e do carbonato de cálcio, respectivamente. } \\
\text { Mais da metade dos informantes ( } 52 \% \text { ) não respondeu corretamente sobre o fato de } \\
\text { o controle do potássio não poder ser feito por meio da alimentação, mas ao mesmo } \\
\text { tempo demonstrou um bom conhecimento referente aos alimentos ricos em potássio, } \\
\text { melhor do que o conhecimento relacionado aos alimentos ricos em fósforo. } \\
\text { Constatou-se, neste estudo, um conhecimento insuficiente pela maior parte dos } \\
\text { participantes, principalmente entre os mais jovens e com menor tempo de } \\
\text { permanência no programa. }\end{array}$ \\
\hline 5 & $\begin{array}{c}\text { MEDEIROS MCWC e SÁ MPC } \\
(2011)\end{array}$ & SCIELO & $\begin{array}{l}\text { Estudo quantitativo. Participaram } 72 \text { indivíduos com doença renal crônica em estágio } \\
\text { IV acompanhados no ambulatório de nefrologia do Hospital das Clínicas da } \\
\text { Universidade Federal de Pernambuco. Neste estudo, constatou-se que a maioria dos } \\
\text { entrevistados apresenta baixo nível socioeconômico e grande dificuldade em realizar } \\
\text { a dieta e terapêutica medicamentosa, havendo necessidade real de reformular o } \\
\text { atendimento destes indivíduos, promovendo maior abordagem interdisciplinar } \\
\text { incluindo atividades educativas. }\end{array}$ \\
\hline 6 & SOUZA FTZ e OLIVEIRA JHA (2017) & ACERVO+ & $\begin{array}{l}\text { Estudo quantitativo. Dos } 61 \text { pacientes entrevistados, } 67,2 \% \text { eram homens e em sua } \\
\text { maioria com idade entre } 41 \text { a } 60 \text { anos. A maioria dos pacientes possuía } \\
\text { acompanhamento nutricional }(96,7 \%) \text {, praticamente não consumia o sal na dieta } \\
(55,7 \%) \text {, líquidos ( } 47,5 \%) \text { e bebida alcoólica }(86,9 \%) \text {. Não realizavam atividades } \\
\text { físicas (68,9\%), e o lazer estava concentrado em passeios }(63,9 \%) \text { e visitas à igreja } \\
(86,9 \%) \text {. A partir disso, pode se configurar uma melhora na avaliação e na elaboração } \\
\text { de estratégias terapêuticas mais aplicáveis e efetivas no manejo desses pacientes, } \\
\text { as quais resultem numa melhora da qualidade de vida e saúde. }\end{array}$ \\
\hline
\end{tabular}




\begin{tabular}{|c|c|c|c|}
\hline $\mathbf{N}$ & Autores (Ano) & Base Científica & Principais achados \\
\hline 7 & LAMBERT K, et al. (2017) & SCIELO & $\begin{array}{l}\text { Estudo qualitativo. O método mais comum de medir a adesão à dieta foram diários de } \\
\text { alimentos ou questionários de adesão. Isso foi seguido por métodos indiretos (por } \\
\text { exemplo, potássio sérico, fosfato ou ganho de peso interdialítico). A taxa média } \\
\text { ponderada de adesão às recomendações dietéticas de ESKD foi de } 31,5 \% \text { e } 68,5 \% \\
\text { para recomendações de líquidos. A adesão às recomendações de proteína, sódio, } \\
\text { fosfato e potássio foram altamente variáveis devido às diferenças nos métodos de } \\
\text { medição usados. Status socioeconômico, idade, suporte social e autoeficácia foram } \\
\text { associados à adesão à dieta. Esta pesquisa pode identificar outros fatores que podem } \\
\text { ter impacto sobre a adesão e podem ser usados para informar o desenho de } \\
\text { estratégias futuras para melhorar a adesão à dieta. }\end{array}$ \\
\hline 8 & GARNEATA L, et al. (2016). & PUBMED & $\begin{array}{l}\text { Estudo qualitativo. Conduzimos um estudo prospectivo, randomizado e controlado de } \\
\text { segurança e eficácia da dieta vegetariana com muito baixa proteína (KD) } \\
\text { suplementada com cetoanálogo, em comparação com a dieta convencional de baixa } \\
\text { proteína (LPD). O desfecho primário foi o início de RRT ou> } 50 \% \text { de redução na e } \\
\text { TFG inicial. A adesão à dieta foi boa, sem alterações nos parâmetros nutricionais e } \\
\text { sem reações adversas. Assim, essa DK parece nutricionalmente segura e pode adiar } \\
\text { o início da diálise em alguns pacientes com DRC. }\end{array}$ \\
\hline 9 & $\begin{array}{l}\text { SCHIEFERDECKER ME, et al. } \\
\qquad(2014)\end{array}$ & LILACS & $\begin{array}{l}\text { Estudo quantitativo. Verificou a composição corporal em pacientes com DRC em } \\
\text { tratamento conservador; bem como a associação da medida do ângulo de fase, com } \\
\text { outros parâmetros nutricionais utilizados na prática clínica. Foram avaliados } 32 \\
\text { pacientes. Verificou-se correlação significativa e positiva entre o } A F \text { com a \%MLG e } \\
\text { com IMME ( } r=0,4541 \text { e } p=0,009 ; r=0,5064 \text { e } p=0,003) \text {. O ângulo de fase foi } \\
\text { significativamente menor em pacientes desnutridos classificados pela ASG }(p=0,01) \text {. } \\
\text { Verificou-se uma correlação positiva e significativa entre } C A \text { e PCR }(r=0,4053 \text { e } \\
p=0,0262) \text {. Nesta casuística, os dados antropométricos indicaram sobrepeso, } \\
\text { obesidade e acúmulo de gordura corporal. O AF parece identificar alterações de } \\
\text { composição corporal que antecedem alterações de parâmetros antropométricos. } \\
\text { Pode-se verificar que a ASG pode ser uma ferramenta adequada na avaliação } \\
\text { nutricional desta população. }\end{array}$ \\
\hline
\end{tabular}

Fonte: Lima GSB, 2021. 


\section{DISCUSSÃO}

No estudo de Medeiros MCWC e Sá MPC (2011) com participação de 72 indivíduos com doença renal crônica em estágio IV realizado no ambulatório de nefrologia do Hospital das Clínicas da Universidade Federal de Pernambuco (HC/UFPE) evidenciou que $65 \%$ dos pacientes não tem conhecimento sobre a doença de base, o que pode dificultar a adesão ao tratamento e o controle da doença. Ainda, $90 \%$ dos pacientes descreveram ter conhecimento da dieta adequada para a doença renal crônica e $93 \%$ receberam orientação quanto à restrição hídrica e dietética, mas $56 \%$ dos pacientes referiram dificuldades para realizar a dieta apropriada ou não se adaptaram, bem como relataram o auxilio de terceiros no preparo dos alimentos, havendo necessidade de reformular o atendimento a estes indivíduos, gerando maior enfoque interdisciplinar e incluindo também as atividades educativas e a participação do familiar ou cuidador.

Lambert K, et al. (2017) corrobora com este estudo ao descrever que vários fatores podem ter impacto sobre a adesão à dieta, mas que podem ser usados para informar o desenho de estratégias futuras para melhorar a adesão a terapêutica.

Segundo Canhestro MR, et al. (2010) o conhecimento adequado do paciente em relação a doença facilita a aceitação do regime terapêutico, incluindo no seu cotidiano uma dieta indicada no tratamento conservador. A totalidade dos informantes deste estudo sabia que o uso dos medicamentos é parte fundamental do tratamento, já que $73,3 \%$ e $56,0 \%$ dos pacientes tinham prescrição do bicarbonato de sódio e do carbonato de cálcio, simultaneamente. Neste mesmo estudo, $52 \%$ dos pacientes não respondeu corretamente sobre como controlar o potássio por meio da alimentação, contudo explanaram melhor sobre os alimentos que contém potássio se comparado ao conhecimento sobre alimentos ricos em fósforo. De tal modo, verificou-se um escasso conhecimento pela maior parte dos participantes, sobretudo naqueles que tem menor tempo de acompanhamento no programa e entre os mais jovens.

Na pesquisa de Souza FTZ e Oliveira JHA (2017) participaram 61 pacientes maiores de 18 anos, na faixa etária de 29 a 80 anos, diagnosticados com doença renal crônica, que estavam em tratamento conservador e foram observados os aspectos referentes à nutrição e $96,7 \%$ dos participantes tinha acompanhamento nutricional, mais da metade desses $(55,7 \%)$ não consumia o sal na sua rotina alimentar, praticamente não consumia líquidos $(47,5 \%)$ e nem bebida alcoólica $(86,9 \%)$. Além disso, soma-se a falta de atividades físicas e atividades de recreação, demandando estratégias terapêuticas mais aproveitáveis e efetivas no manejo desses pacientes, as quais resultem numa melhora da qualidade de vida e saúde.

No que diz respeito ao consumo de líquidos, os pacientes com doença renal crônica devem restringir o consumo de líquidos entre 1000 a 1500/mL/dia, prevenindo assim a sobrecarga de líquidos no aparelho renal (LAMBERT K, et al., 2017).

Os pacientes adultos com doença renal crônica identificados no estudo de Thees TYP, et al. (2018) pela classificação do Índice de Massa Corporal (IMC) apresentavam-se eutróficos (18,2\%), 18,2\% sobrepeso, $33,3 \%$ obesos grau I, $21,2 \%$ obesos grau II e $9,1 \%$ obesos grau III. Já os idosos, $7,1 \%$ estavam abaixo do peso, $36,8 \%$ apresentaram eutrofia e $56,1 \%$ com sobrepeso, apontando baixa frequência de desnutrição nesses idosos. A amostra foi composta por 188 indivíduos, mais da metade (59\%) pertencente ao sexo masculino, com idade média de 69 anos. A maioria encontrava-se no estágio 3B $(35,1 \%)$ ou quatro da doença renal crônica (34\%). Vale lembrar que a avaliação do estado nutricional é fundamental, impactando na qualidade de vida desses pacientes.

Ao averiguar a composição corporal em pacientes adultos com doença renal crônica em tratamento conservador Schieferdecker ME, et al. (2014) descrevem dados antropométricos que indicam sobrepeso, obesidade e acúmulo de gordura corporal, admitindo que o uso de técnicas para avaliação nutricional (antropométricas, bioquímicas e impedância elétrica) auxiliam no prognóstico da doença e além disso, confirmam o que a literatura cientifica mundialmente descreve sobre obesidade e sua relação com a doença renal crônica.

Castro MCM (2018) descreve que a demasiada ingestão de proteínas, em especial de origem animal, sobrecarrega a função renal desencadeando sintomas gastrointestinais como náuseas, vômitos e anorexia, 
o que altera o estado nutricional do paciente. Também descreve a necessidade de restrição de sal e de determinadas frutas, legumes e verduras, para o controle do potássio sérico, adequando a dieta ao estágio da doença, pois é uma poderosa ferramenta no controle dos sintomas da doença renal crônica.

Mansur HN, et al. (2012) ao estudar quantitativamente a relação da prevalência da fragilidade (fraqueza muscular e exaustão) em pacientes com doença renal crônica caracterizou que a mesma estava presente em $36 \%$ dos pacientes em tratamento conservador, 37,8\% em hemodiálise e 47,8\% em diálise peritoneal, sugerindo, dentre vários fatores, o não uso de vitamina $\mathrm{D}$. A doença renal crônica provoca uma redução na produção de vitamina $D$ e igualmente na sua conversão, o que fez com que a KDIGO recomendasse os protocolos para a correção da hipovitaminose D (ZHA Y e QIAN Q, 2017).

A condição de fragilidade é um estado clínico em que o paciente apresenta grande vulnerabilidade do organismo a agentes agressores/estressores, sendo comum em idosos, restringindo as reservas fisiológicas desses indivíduos (MANSUR HN, et al., 2012).

No tratamento conservador o enfoque dietético é todo baseado na função renal que está diminuída, devendo ser reduzida a carga filtrada pelos rins, de modo a controlar a excreção das toxinas, mas a literatura cientifica não aponta uma dieta renal padrão para tratar os pacientes com doença renal crônica. Entretanto, descreve que pacientes renais crônicos em estágios precoces devem modificar sua ingestão de proteínas e sódio, ou seja, os minerais fosfato, sódio e potássio devem ser suavizados e micronutrientes como vitaminas A, C, D, zinco e selênio devem ter um aporte maior. Dados que evidenciam a frequente dificuldade dos pacientes na adesão ao tratamento e suas consequências nutricionais que desfavorecem a saúde (LAMBERT K, et al., 2017).

Nas últimas décadas tem se estudado o padrão alimentar vegetariano como uma boa estratégia para o controle das complicações em pacientes com doença renal crônica, pois esses apresentam um melhora relativa na taxa de filtração glomerular ao aderir à dieta, sem mostrar alterações nutricionais nem reações adversas se comparada a dieta com muito baixa proteína. Assim, a dieta vegetariana parece nutricionalmente segura e pode adiar o início da diálise em alguns pacientes com doença renal crônica (GARNEATA L, et al., 2016).

\section{CONSIDERAÇÕES FINAIS}

O diagnóstico precoce da doença renal crônica, o encaminhamento imediato para acompanhamento com nefrologista e a prática de medidas para retardar a progressão da doença são as estratégias básicas para o correto controle da doença, e sua evolução está relacionada à qualidade do tipo de tratamento realizado, por isso a importância da abordagem multidisciplinar desses indivíduos. Vários são os fatores que dificultam a adesão ao correto tratamento, mas as restrições nutricionais representam o maior desafio do tratamento conservador da doença renal crônica, pois exige uma mudança dos hábitos não apenas do paciente, mas de todos os familiares. A dieta para indivíduos com doença renal crônica devem ser adequadas às necessidades de cada indivíduo, prevenindo desnutrição e garantindo a adesão dos clientes.

\section{REFERÊNCIAS}

1. ALCALDE PR, KIRSZTAJN GM. Gastos do Sistema Único de Saúde brasileiro com doença renal crônica. Brazilian Journal Nephrology, 2018; 40(2):122-129.

2. COUSER WG, et al. The contribution of chronic kidney disease to the global burden of major noncommunicable diseases. Kidney International, 2011; 80(12):1258-1270.

3. CANHESTRO MR, et al. Conhecimento de pacientes e familiares sobre a doença renal crônica e seu tratamento conservador. Revista Mineira de Enfermagem, 2010; 14(3): 335-344.

4. CASTRO MCM. Tratamento conservador de paciente com doença renal crônica que renuncia à diálise. Jornal Brasileiro de Nefrologia. [conectados], 2019; 41(1):95-102.

5. GABAY C, KUSHNER I. Acute-phase proteins and other systemic responses to inflammation. New England Journal of Medicine, 1999; 340(6): 448-454.

6. GARNEATA L, et al. Ketoanalogue Supplemented Vegetarian Very Low-Protein Diet and CKD Progression. J Am Soc Nephrology, 2016; 27(7):2164-76. 
7. GRICIO TC, et al. Percepções e conhecimentos de pacientes com doença renal crônica em tratamento conservador. Revista Eletrônica de Enfermagem [Internet], 2009; 11(4):884-93.

8. KALANTAR-ZADEH K, et al. Appetite and inflammation, nutrition, anemia, and clinical outcome in hemodialysis patients. The American Journal of Clinical Nutrition, 2004; 80 (2): 299-307.

9. KDOQI. Clinical Practice Guidelines for Chronic Kidney Disease: evaluation, classification, and stratification. American Journal of Kidney Disease. 2002; 39(2), 1-266.

10. LAMBERT K, et al. An integrative review of the methodology and findings regarding dietary adherence in end stage kidney disease. BMC Nephrology, 2017; 18(1):318.

11. MARINHO IG, et al. Fatores de risco para doenças crônicas não-transmissíveis em moradores no entorno de áreas alagadas na periferia de Macapá, Amapá. Brazilian Journal Health Review, 2018; 1(1), 148-163.

12. MANSUR HN, et al. Prevalência da fragilidade entre os pacientes com doença renal crônica em tratamento conservador e em diálise. Brasilian Journal of Nephrology [online], 2012; 34(2), 153-160.

13. MEDEIROS MCWC, SÁ MPC. Adesão dos portadores de doença renal crônica ao tratamento conservador. Revista RENE, 2011; 12(1): 65-72.

14. MINAYO MCS. Análise qualitativa: teoria, etapas e fidedignidade. Ciênc. saúde coletiva (Internet),2012; 17(3):621626.

15. PEREIRA RA, et al. Dieta na doença renal crônica: uma abordagem integrada à terapia nutricional. Revista da Associação Médica Brasileira. [conectados], 2020; 66 (1): s59-s67.

16. PERUSSO FKG, et al. Alimentação e hábitos de vida na doença renal crônica. Revista Caderno de Medicina, 2019; 2(2).

17. RASCHE J, BOSCO SMD. Doença Renal Crônica: Estudo De Caso. Revista Destaques Acadêmicos, $2015 ; 7$ (3).

18. RIELLA MC. Princípios básicos de nefrologia e distúrbios hidroeletrolíticos. Rio de Janeiro: Guanabara Koogan, 2003 , 1068p.

19. ROSO CC, et al. O cuidado de si de pessoas em tratamento conservador da insuficiência renal crônica. [s.l.]: Texto Contexto Enfermagem, 2013; 22(3): 739-45.

20. SOUZA FTZ, OLIVEIRA JHA. Sintomas depressivos e ansiosos no paciente renal crônico em tratamento conservador. Revista Psicologia e Saúde [online], 2017; 9(3): 17-31.

21. SCHIEFERDECKER ME, et al. Composição corporal de pacientes com doença renal crônica em tratamento conservador. Revista Médica da UFPR, 2014; 1(2): 47-53.

22. SOCIEDADE BRASILEIRA DE NEFROLOGIA (SBN). Censo $2017 . \quad$ Disponível em: https://arquivos.sbn.org.br/uploads/sbninforma114.pdf. Acessado em: 20 de dezembro de 2020.

23. SZUSTER DAC, et al. Sobrevida de pacientes em diálise no SUS no Brasil. [s.I.]: Caderno de Saúde Pública, 2012; 415-424.

24. THEES TYP, et al. Avaliação antropométrica e bioquímica de portadores da doença renal crônica em tratamento conservador. Nutrición clínica y Dietética Hospitalaria, 2018; 38(4):75-81.

25. UNA-SUS/ Universidade Federal do Maranhão - UFMA. Política nacional da atenção ao portador de doença renal no Sistema Único de Saúde/Ministério da Saúde (Org.). - São Luís, 2014.22f.

26. WING MR, et al. Race modifies the association between adiposity and inflammation in patients with chronic kidney disease: Findings from the chronic renal insufficiency cohort study. Obesity, 2014; 22: 1359-1366.

27. ZHA Y, QIAN Q. Protein Nutrition and Malnutrition in CKD and ESRD. Nutrients, 2017; 9(3). 